\title{
Reclaimed water as a reservoir of antibiotic resistance genes: distribution system and irrigation implications
}

\author{
Nicole Fahrenfeld ${ }^{1}$, Yanjun Ma ${ }^{1}$, Maureen O'Brien $^{2}$ and Amy Pruden ${ }^{1}$ * \\ 1 Department of Civil and Environmental Engineering, Virginia Tech, Blacksburg, VA, USA \\ ${ }^{2}$ Department of Civil and Environmental Engineering, Colorado School of Mines, Golden, CO, USA
}

\section{Edited by:}

Jun Lin, The University of Tennessee, USA

\section{Reviewed by:}

Timothy LaPara, University of Minnesota, USA

Paul D. Brown, University of the West Indies, Jamaica

\section{*Correspondence:}

Amy Pruden, Department of Civil and Environmental Engineering, Virginia Tech, 418 Durham Hall, Blacksburg, VA 24060, USA.

e-mail.apruden@vt.edu

\begin{abstract}
Treated wastewater is increasingly being reused to achieve sustainable water management in arid regions. The objective of this study was to quantify the distribution of antibiotic resistance genes (ARGs) in recycled water, particularly after it has passed through the distribution system, and to consider point-of-use implications for soil irrigation. Three separate reclaimed wastewater distribution systems in the western U.S. were examined. Quantitative polymerase chain reaction ( $(\mathrm{PCCR}$ ) was used to quantify ARGs corresponding to resistance to sulfonamides (su/1, su/2), macrolides (ermF), tetracycline [tet $(\mathrm{A})$, tet $(\mathrm{O})$ ], glycopeptides (vanA), and methicillin (mecA), in addition to genes present in waterborne pathogens Legionella pneumophila (Lmip), Escherichia coli (gadAB), and Pseudomonas aeruginosa (ecf $\mathrm{x}, g y r \mathrm{~B})$. In a parallel lab study, the effect of irrigating an agricultural soil with secondary, chlorinated, or dechlorinated wastewater effluent was examined in batch microcosms. A broader range of ARGs were detected after the reclaimed water passed through the distribution systems, highlighting the importance of considering bacterial regrowth and the overall water quality at the point of use (POU). Screening for pathogens with qPCR indicated presence of Lmip and gadAB genes, but not ecfx or gyrB. In the lab study, chlorination was observed to reduce 16S rRNA and sul2 gene copies in the wastewater effluent, while dechlorination had no apparent effect. ARGs levels did not change with time in soil slurries incubated after a single irrigation event with any of the effluents. However, when irrigated repeatedly with secondary wastewater effluent (not chlorinated or dechlorinated), elevated levels of sul1 and sul2 were observed. This study suggests that reclaimed water may be an important reservoir of ARGs, especially at the POU, and that attention should be directed toward the fate of ARGs in irrigation water and the implications for human health.
\end{abstract}

\section{Keywords: antibiotic resistance genes, water reuse, reclaimed water distribution systems, irrigation}

\section{INTRODUCTION}

Water reuse is an increasingly common sustainable water management practice motivated by climate change, urbanization, energy efficiency, and environmental protection (US Environmental Protection Agency [USEPA], 2012). Reclaimed or recycled wastewater is treated by municipalities for a variety of purposes, including non-potable urban reuse (Grant et al., 2012; USEPA, 2012). In the United States Environmental Protection Agency (USEPA) guidelines on water reuse, the presence of antibiotics as trace organic contaminants in wastewater is noted and a need for more information is acknowledged to reduce the proliferation of antibiotic resistance and protect public health (USEPA, 2012).

Antibiotic resistance proliferation is currently outpacing the development of novel antibiotics, calling for effective strategies to mitigate the spread of antibiotic resistance (Carlet et al., 2012). Bacterial resistance to antibiotics is partially conferred through antibiotic resistance genes (ARGs), which code for specific antimicrobial functions such as efflux pumps (Webber and Piddock, 2003). ARG contamination has been quantified in a variety of environmentally relevant matrices, including wastewater treatment plant (WWTP) effluent, which is known to contribute to ARG loadings in surface waters (Pruden et al., 2013; Storteboom et al., 2010; LaPara et al., 2011). Some states require chlorine or UV disinfection for reused water (USEPA, 2012) and certain disinfectants (free chlorine, $\mathrm{O}_{3}$, and $\mathrm{UV}$ ) are capable of reacting with nucleic acids during treatment and therefore may potentially reduce ARGs, as recently reviewed by Dodd (2012). However, McKinney and Pruden (2012) recently demonstrated in a controlled lab study that typical UV doses applied at WWTPs are capable of reducing antibiotic resistant strains of bacteria, but not ARGs. Others have noted little reduction in ARGs following UV effluent treatment in full-scale WWTPs (Auerbach et al., 2007; Kim et al., 2010).

While WWTPs are now well-established as a reservoir of ARGs (Auerbach et al., 2007; Kim et al., 2010; Czekalski et al., 2012), and some have considered effect of irrigation with reclaimed water (McLain and Williams, 2012; Negreanu et al., 2012), there is a void of studies focused on the potential for re-growth in treated wastewater distribution systems ("purple" pipes). In one study examining soil irrigated with treated wastewater, no differences in the microbiome or ARG levels were observed compared to soil irrigated with fresh water (Negreanu et al., 2012). In fact, in Llobregat (NE Spain), reclaimed water emitted to a river 
had lower concentrations of indicator organisms than the stream water (Rubiano et al., 2012). In contrast, re-growth of indicator organisms has been observed between the point of entry (POE) and point of use (POU) in reclaimed water systems (Ryu et al., 2005), raising the question of whether ARGs can also increase during distribution. In a study examining drinking water distribution systems, antibiotic resistant bacteria were shown to decrease between POE and POU, but ARGs were observed to increase (Xi et al., 2009).

In this study, ARG occurrence patterns were evaluated in the POU water in three arid western U.S. recycled water distribution systems using quantitative polymerase chain reaction (qPCR). Depending on access, POE, POU biofilm, and soil irrigated with recycled water were also examined. Samples were also screened by qPCR for the potential presence of known waterborne pathogenic bacteria and indicators, Legionella pneumophila, Escherichia coli, and Pseudomonas aeruginosa. To simulate the effect of reused water for irrigation, a series of batch laboratory soil microcosm studies were performed to compare irrigation with secondary, chlorinated, and dechlorinated effluent from a representative conventional WWTP.

\section{MATERIALS AND METHODS WATER REUSE SYSTEMS}

Samples were collected from three non-potable reclaimed wastewater distribution systems in the western U.S., together served by four WWTPs (Table 1). Water samples (-POE or -POU) were collected in sterile centrifuge tubes. Biofilm (-F) was collected with a sterile swab, and packed in a sterile centrifuge tube. A soil sample was collected from a field irrigated with reclaimed wastewater $(-S)$, in a sterile centrifuge tube. All samples were shipped overnight on ice and stored frozen until extraction. Water samples were freezedried prior to DNA extraction (FreeZone Plus, Labconco, Kansas City, MO, USA).

\section{BATCH MICROCOSMS}

Aerobic, batch microcosms were prepared to investigate two water reuse scenarios on historically manured soil: (1) a single irrigation event ("batch irrigation") and (2) repeated irrigation events ("periodic irrigation"). Soil was collected (upper 7.5-10 cm) in winter from historically manured corn fields near Virginia Tech campus using a soil probe. Soil was air dried and sieved $(2 \mathrm{~mm})$, and an

Table 1 | Summary of reclaimed WWTP tertiary treatment characteristics.

\begin{tabular}{|c|c|c|c|c|}
\hline & $A a^{1}$ & $A b^{1}$ & B & C \\
\hline Capacity (Mgd) & 6 & 4 & 1.1 & 0.6 \\
\hline Filtration & Media & Dual media & Carbon filter & $\begin{array}{l}\text { Sand }+ \text { activated } \\
\text { carbon }\end{array}$ \\
\hline Disinfection & Chlorine & UV & Chlorine & Chlorine \\
\hline
\end{tabular}

All WWTPs studied use conventional primary and secondary treatment processes.

${ }^{1} \mathrm{Aa}$ and $\mathrm{Ab}$ are separate WWTPs that emit water to a commingled distribution system. aliquot was preserved for DNA extraction. For each study, microcosms were prepared in $250 \mathrm{~mL}$ flasks in triplicate with $50 \mathrm{~g}$ of soil and incubated at room temperature on a shaking table to maintain aerobic conditions. Slurry samples were collected weekly without sacrifice. Secondary, chlorinated, and dechlorinated WWTP effluents were collected before each irrigation treatment event from a representative 4.5 Mgd Domestic WWTP.

Batch irrigation soil was initially treated with $80 \mathrm{~mL}$ of freshly collected WWTP effluent fractions. Slurry samples ( $\sim 0.4$ g wet $)$ were collected and an equal volume of deionized (DI) water was added to each flask to maintain soil moisture. WWTP effluent fractions $(2-4 \mathrm{~L})$ were filtered through $0.22 \mu \mathrm{m}$ membrane and total DNA was extracted from the filter, as described below. The periodic irrigation soil was initially treated with $100 \mathrm{~mL}$ of freshly collected WWTP effluent fractions. Slurry samples $(10 \mathrm{~mL})$ were collected, centrifuged at $3,300 \times g$ for $5 \mathrm{~min}$, and $0.4 \mathrm{~g}$ of the pellet was used for DNA extraction. Fresh WWTP effluent fractions were added to the flasks to replace the volume removed during each sampling. WWTP effluent fractions $(60 \mathrm{~mL})$ were freeze-dried, as above, and DNA was extracted from the residuals.

\section{MOLECULAR TECHNIQUES}

DNA was extracted from freeze-dried water/slurry, $0.4 \mathrm{~g}$ soil, or swabs using a FastDNA ${ }^{\circledR}$ SPIN Kit for Soil (MP Biomedicals, Solon, $\mathrm{OH}, \mathrm{USA}$ ) and diluted 1:50 or 1:100 for the water reuse field study and 1:30 for the irrigation studies prior to downstream analysis. qPCR was performed to quantify $16 \mathrm{~S}$ rRNA (Suzuki et al., 2000), sul1 (Aminov et al., 2001), sul2 (Aminov et al., 2001), tet(A) (Aminov et al., 2002), tet(O) (Aminov et al., 2001), ermF (Chen et al., 2007), vanA (Dutka-Malen et al., 1995), mecA (McKinney and Pruden, 2012), L. pneumophila-specific mip (Nazarian et al., 2008), E. coli-specific gadAB (Chen et al., 2006), and P. aeruginosa-specific ecf X/gyrB (Anuj et al., 2009) genes for the water reuse field study. Reaction matrix and PCR protocols were as previously described (Ma et al., 2011; Wang et al., 2012). For the irrigation study, $16 \mathrm{~S}$ rRNA, sul1, sul2, tet $(\mathrm{O})$, and tet $(\mathrm{W})$ genes were monitored. All standard curves of qPCR were constructed from serial dilutions of cloned genes ranging from $10^{8}$ to $10^{2}$ gene copies/ $\mu \mathrm{L}$. Samples were analyzed in triplicate with a standard curve and negative control included in each run. Limits of quantification with respect to sample volume varied depending on the volume processed and the dilution of DNA extract, ranging from -1.4 to $0.6 \log _{10}$ gene copies/mL, 3.1-5.1 $\log _{10}$ gene copies per swab, and $0.5-2.5 \log _{10}$ gene copies/g of soil. Additionally, cloning and sequencing of qPCR product was performed for assays that had not been validated previously (vanA) to demonstrate specificity of PCR product (GenBank accession number KC792557-KC792573).

\section{STATISTICS}

Cluster analysis was performed on transformed (square root) $16 \mathrm{~S}$ rRNA gene normalized ARG profiles from the reclaimed wastewater systems and significance testing was carried out using the SimProf test in PrimerE (Plymouth, UK). To compare between wastewater treatment effluent fractions and treatments in the irrigation study, data was Box-Cox transformed. Transformed data were compared using ANOVA, and significant differences 
$(p<0.05)$ were determined using Tukey's honest significance test, as implemented in R (http://www.r-project.org/). Multiple comparisons for the distribution system and irrigation studies were performed on Box-Cox transformed data using least square means comparison with a Satterthwaite estimation of degrees of freedom in SAS, again using Tukey adjustment for multiple comparisons. Linear modeling for the irrigation study data was performed in Microsoft Excel.

\section{RESULTS}

\section{ARG OCCURRENCE PATTERNS IN RECYCLED WATER}

Antibiotic resistance genes were detected in all water reuse samples (Figures 1 and 2). The most frequently detected ARGs were vanA, ermF, and sul2 with frequencies of detection of 100,73 , and $65 \%$ ( $n=23)$, respectively. tet $(\mathrm{O})$ had the lowest frequency of detection $(17 \%, n=23)$ other than mecA, which was not detected in any of the samples. For System A, significant differences in ARG

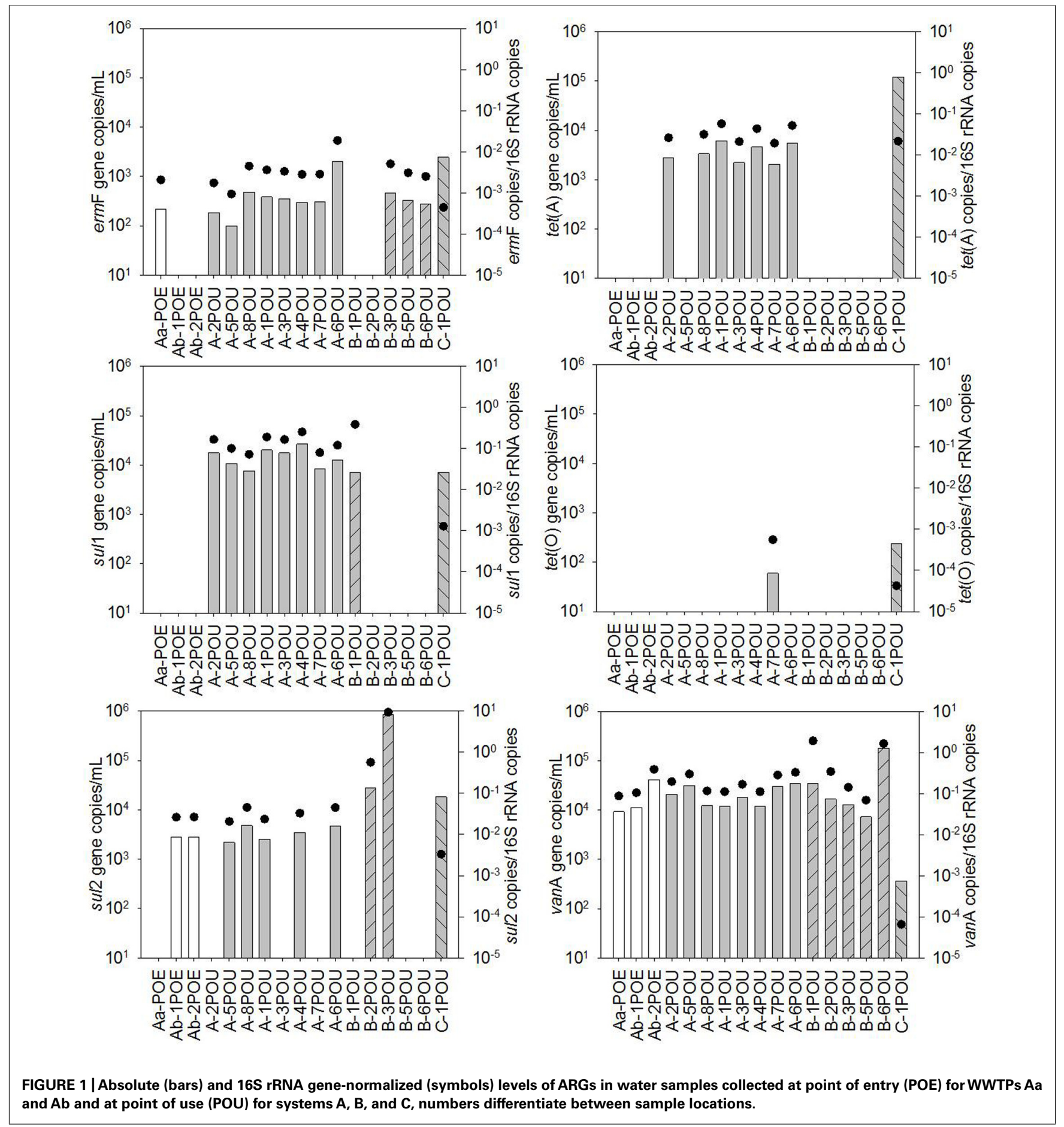




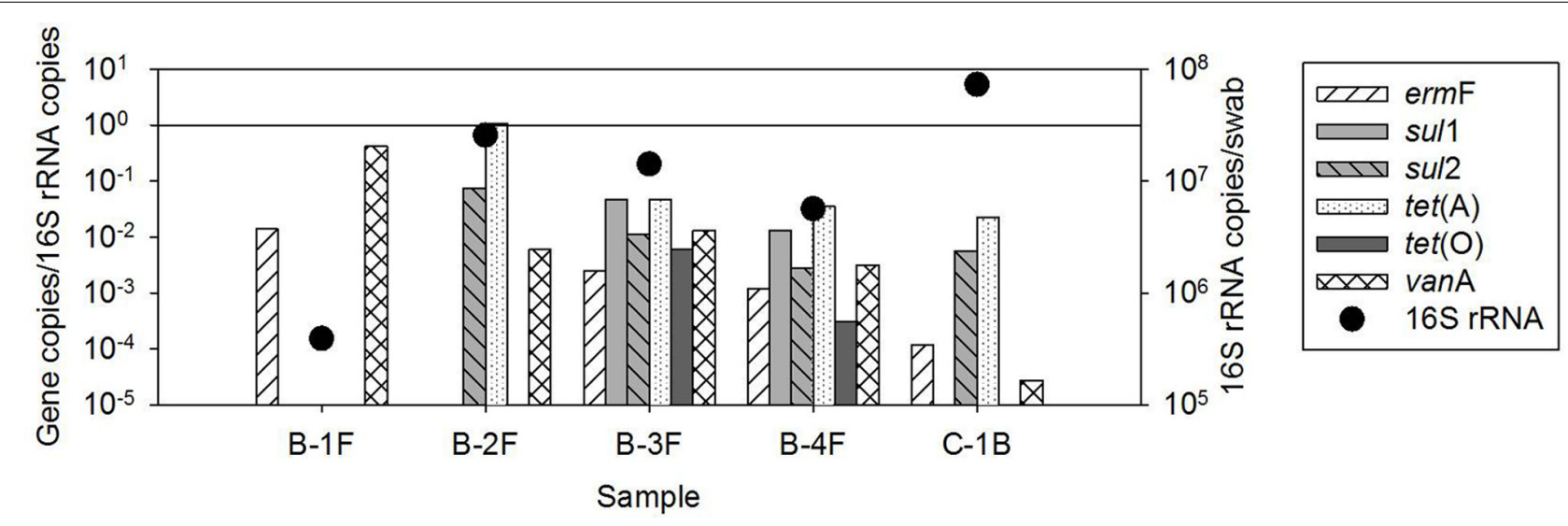

FIGURE 2 | Quantification of ARGs in biofilm samples available from recycled water distribution systems B and C. Bars represent absolute ARG copies per swab, symbols represent $16 \mathrm{~S}$ rRNA gene copies per swab.

concentrations were observed between POE and POU for sull and tet (A), $p<0.001$ for both. Concentrations of vanA, ermF, and sul2, $16 \mathrm{~S}$ rRNA, and tet $(\mathrm{O})$ were not significantly different between POE and POU ( $p=0.33-0.99)$.

In the irrigated soil sample (B-7S), 9.5, 7.3, 7.2, and $5.6 \log _{10}$ gene copies/g of soil were quantified for 16S rRNA, sul1, sul2, and vanA, respectively; ermF, tet $(\mathrm{A})$, and tet $(\mathrm{O})$ were below detection. Normalizing ARGs to $16 \mathrm{~S}$ rRNA gene copy numbers indicated that sul1 and sul2 were one to two orders of magnitude lower and vanA three to five orders of magnitude lower in the soil sample than observed in water and biofilm samples.

The occurrence of ARGs varied among the five biofilm samples examined, ranging from two to six classes of ARGs (Figure 2). However, individual ARG levels in the biofilm did not correlate with corresponding bulk water ARGs among the available paired samples (Figure 3). For example, the most abundant ARG, tet(A), in $\mathrm{B}-2 \mathrm{~F}$ was below detection in $\mathrm{B}-2 \mathrm{POU}$.

Cluster analysis performed on 16S rRNA gene normalized ARG profiles considered both the kinds of ARGs detected and their frequencies and resulted in several significantly different sample clusters (Figure 4). Generally, three distinct clusters were formed primarily by POE, WWTP-A POU, and WWTP-C POU samples, while the WWTP-B POU samples were interspersed among the three clusters, and a fourth cluster consisting only of WWTP-B samples. The three WWTP-A POE samples formed a significantly different cluster from POU samples in its corresponding distribution system (50\% similarity). POU samples from System A $(n=7)$ formed a cluster with $78-96 \%$ similarity, except A-5POU which was significantly different $(71 \%)$ and clustered with some samples from System B $(n=5)$. No patterns were observed in the biofilm and water clustering patterns for paired samples $(n=4)$. Biofilms did not cluster with one another nor did biofilm samples cluster with paired water sample with similarities ranging from $16 \%$ for F2 and F3 (significantly different) to $100 \%$ for F1 (no difference). The soil sample (B$7 \mathrm{~S}$ ) clustered with other B system biofilm and water samples, which were only $20 \%$ similar to the remainder of the samples selected.

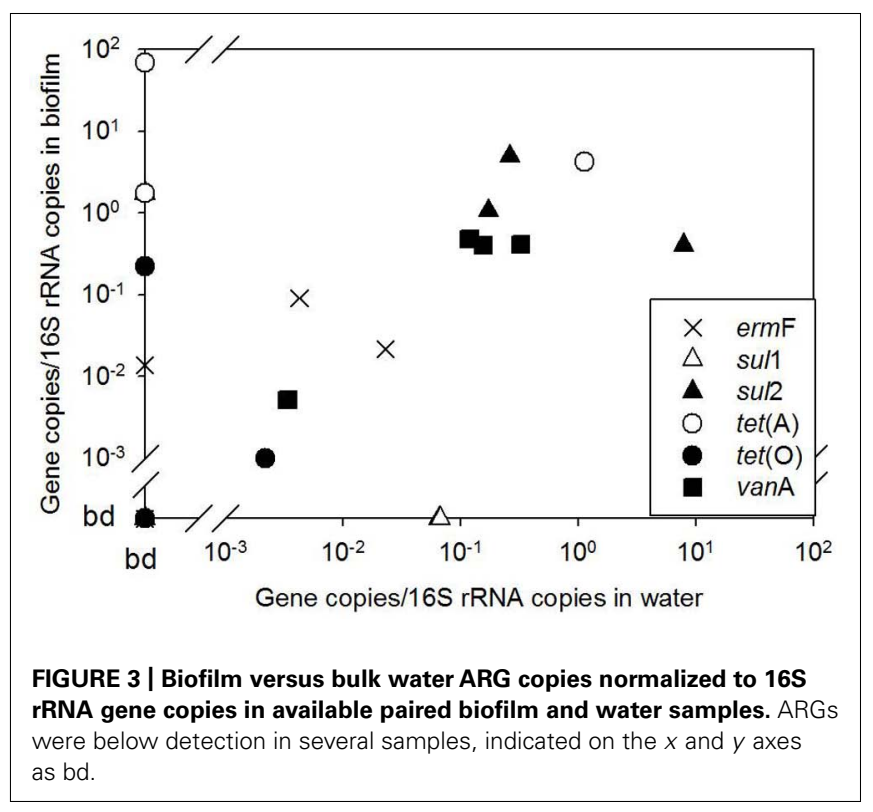

\section{WATERBORNE PATHOGEN AND FECAL INDICATOR SCREENING}

Quantitative PCR screening for E. coli and L. pneumophila through gad $\mathrm{AB}$ and mip resulted in positive detections for $48 \%$ of samples: 35 and $17 \%$ for gadAB and mip, respectively (Table 2). ecrfX/gyrB, corresponding to $P$. aeruginosa, were below detection in all samples.

\section{ARGs DURING SIMULATED LAND APPLICATION WWTP effluent fraction ARG loads}

Levels of ARGs in secondary, chlorinated, and dechlorinated WWTP effluent are compared in Figure 5. sull was the most frequently detected ARG (100\%), followed by sul2 (71\%), tet(W) $(71 \%)$, and $\operatorname{tet}(\mathrm{O})(61 \% ; n=21)$. Comparing the ARGs and $16 \mathrm{~S}$ rRNA gene levels across effluent fractions, secondary effluent was significantly higher than chlorinated and dechlorinated (both $p<0.0001)$ effluents, which were not significantly different from each other $(p=0.45)$. Comparing by gene across effluent fractions, 


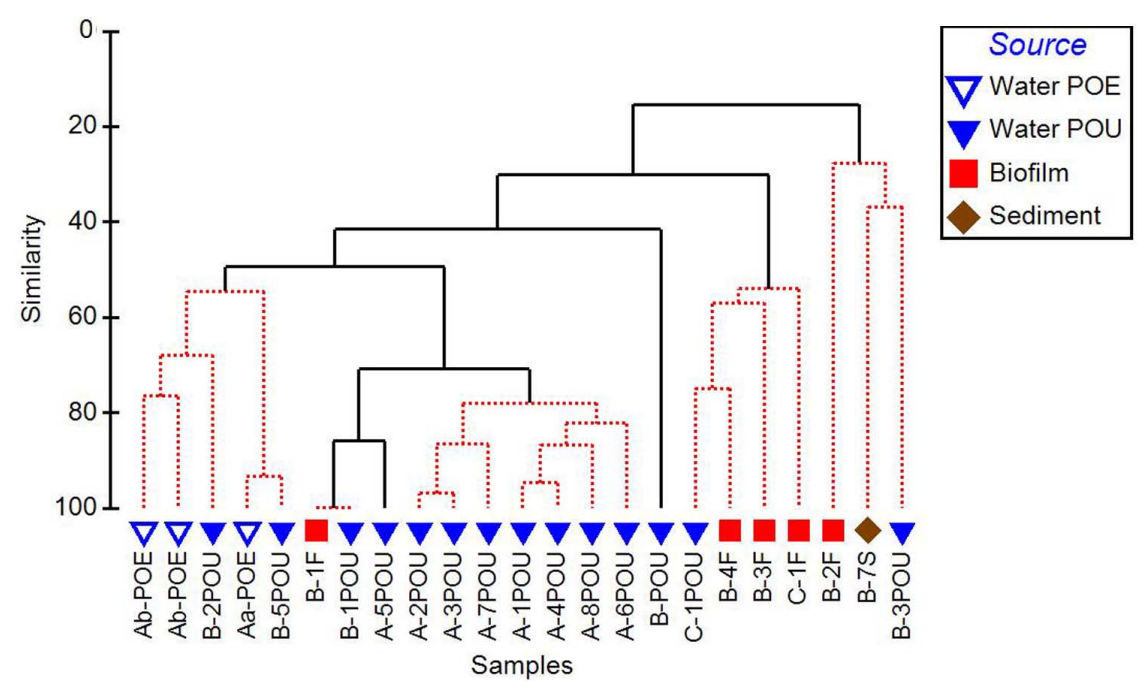

FIGURE 4 | Cluster analysis of 16S rRNA gene normalized ARG copy numbers, considerate of class and relative abundance of each ARG measured in the distribution systems ( $A a, A b, B, C$ ) and across environmental matrices (POE, point of entry water; POU, point of use water; F, biofilm; S, soil). Solid branches indicate significantly different clusters $(p<0.05)$.

\begin{tabular}{|c|c|c|}
\hline Sample & gadAB & mip \\
\hline Ab-POE & 3.7 & bd* \\
\hline A-1POU & 4.2 & $\mathrm{bd}$ \\
\hline $\mathrm{A}-2 \mathrm{POU}$ & 5.1 & 1.8 \\
\hline A-3POU & 4.4 & $\mathrm{bd}$ \\
\hline A-8POU & 5.3 & $\mathrm{bd}$ \\
\hline B-1POU & $b d$ & 1.4 \\
\hline C-1POU & 6.6 & $\mathrm{bd}$ \\
\hline B-1F & $\mathrm{bd}$ & 4.6 \\
\hline $\mathrm{B}-2 \mathrm{~F}$ & 6.0 & $\mathrm{bd}$ \\
\hline $\mathrm{C}-1 \mathrm{~F}$ & 6.9 & $\mathrm{bd}$ \\
\hline B-7S & $\mathrm{bd}$ & 5.6 \\
\hline
\end{tabular}

*bd, below detection.

secondary effluent and chlorinated effluent were significantly different in terms of 16S rRNA and sul 2 gene copies $(p<0.0001$ for both). Interestingly, when ARGs were normalized to $16 \mathrm{~S}$ rRNA gene copies, significant differences were not observed among the secondary, chlorinated, or dechlorinated effluents $(p=0.29-0.91)$. This suggests no preferential destruction of specific gene types by chlorination.

\section{Irrigation studies}

Results of the batch irrigation study (Figure 6) indicated no difference between soil irrigated with secondary, chlorinated, or dechlorinated effluent, or DI water in terms of ARG concentration with time for sul1, sul2, tet $(\mathrm{O})$, or $\operatorname{tet}(\mathrm{W})(p>0.405$ for all, except for sul2 deionized $p=0.05$ and secondary effluent $p=0.006$ ).

Soil periodically irrigated resulted in a significant increase in sul2 when receiving secondary effluent, compared to irrigation with the other water types ( $p$ ranging from 0.032 to $p<0.0001$; Figure 7). Additionally, soil irrigated with secondary effluent had significantly higher sull copies than that irrigated with chlorinated effluent, dechlorinated effluent, or DI water (all $p<0.0001$ ). No significant difference across time was observed among the irrigation water types for $\operatorname{tet}(\mathrm{O})(p=0.13-1.0)$ or $\operatorname{tet}(\mathrm{W})(p=0.74-1.0)$. Linear modeling of gene copies versus time revealed an increasing trend of sul2 copies with time in soil irrigated with secondary effluent $\left(R^{2}=0.92\right)$.

\section{DISCUSSION}

This study explored the occurrence of several ARGs in three reclaimed water distribution systems in the U.S. Given limited access to such systems, only one sampling event was possible. Nonetheless, the results provide important baseline information to support future research, including insight into the kinds of ARGs, bacteria, and applications that may be of concern. To the knowledge of the authors, this is the first study specifically investigating the potential for ARGs to persist or amplify within the reclaimed water distribution pipes.

\section{ARG OCCURRENCE IN RECYCLED WATER DISTRIBUTION SYSTEMS}

Several ARGs were detected at the POU in this study, many of which were below detection at the POE. This highlights the need to consider microbiological processes occurring in reclaimed water distribution systems that may be contributing to ARG amplification and suggests that focus on the water quality at the POU may be the most appropriate for assessing risk. Re-growth is a well-known 


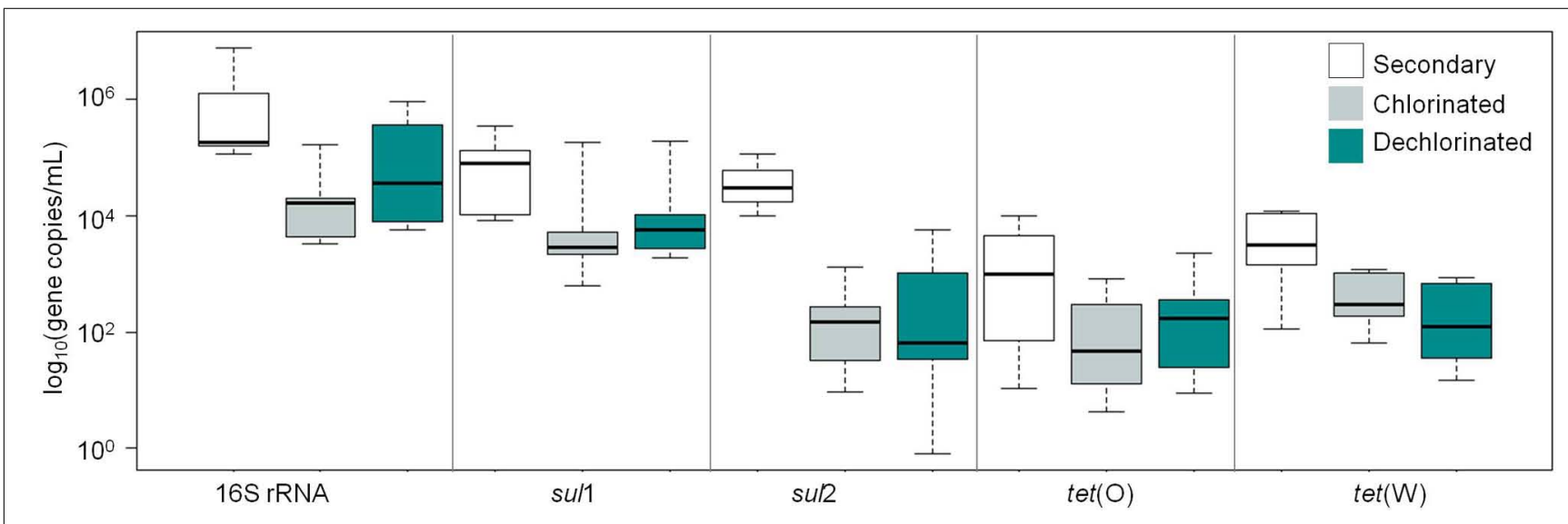

FIGURE 5 | Censored boxplot of 16S rRNA genes, sul1, sul2, tet(0), and tet(W) gene copies per milliliter in secondary (no fill), chlorinated (gray), and dechlorinated (blue) domestic WWTP effluents applied in the batch (2-4 L $0.22 \mu \mathrm{m}$ filtered) and periodic (60 mL freeze-dried) irrigation study ( $n=6$ tet genes, 7 sul and 16S rRNA genes).
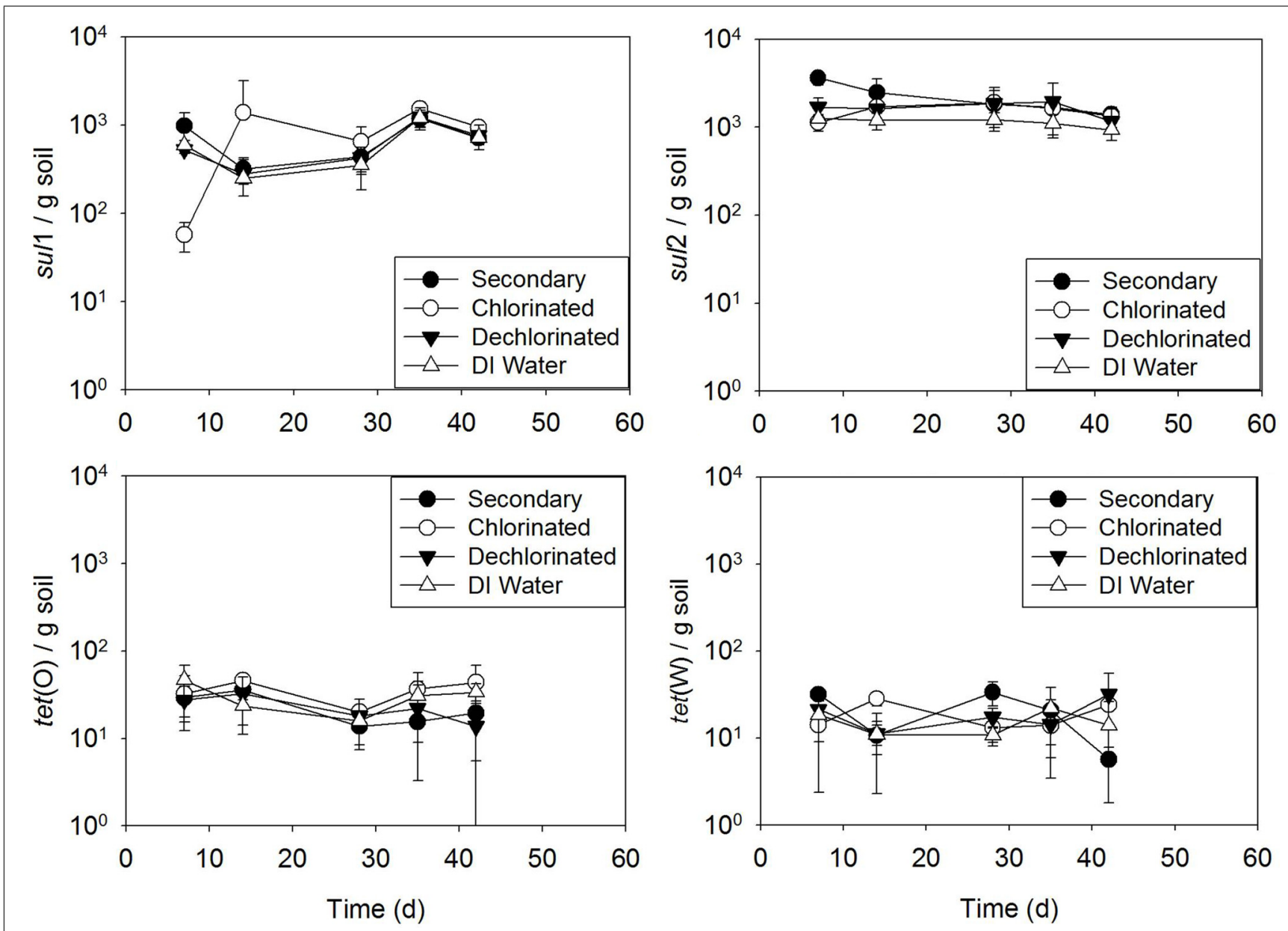

FIGURE 6 | sul1, sul2, tet(0), and tet(W) genes in soils subject to one time (batch) irrigation with secondary, chlorinated, dechlorinated domestic WWTP effluents and deionized (DI) water, per gram of soil (slurry). Error bars represent standard deviation of triplicate microcosms. 

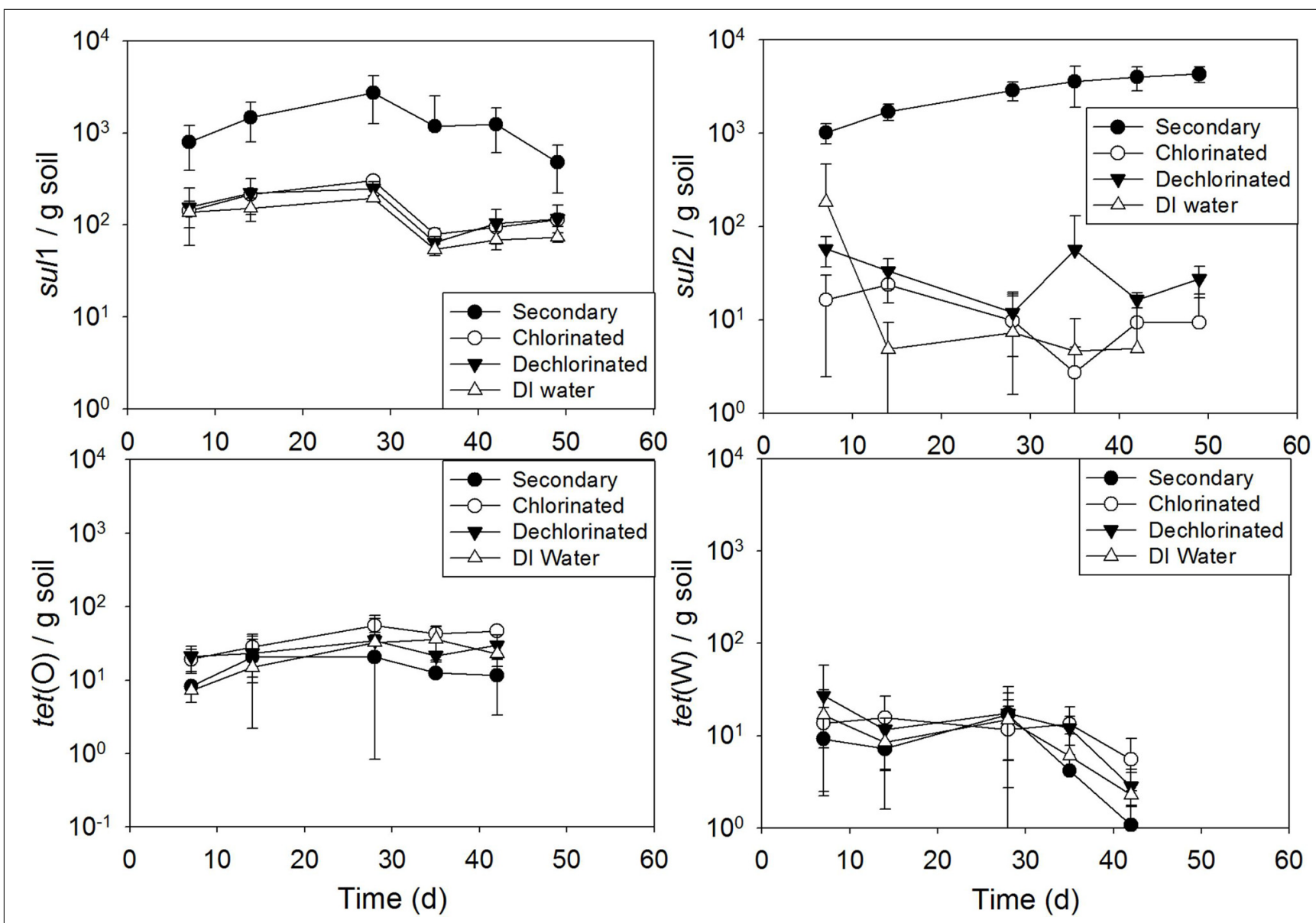

FIGURE 7 | sul1, sul2, tet $(0)$ and tet(W) genes in soils periodically irrigated with secondary, chlorinated, dechlorinated domestic WWTP effluents and deionized (DI) water, normalized to soil mass (wet weight). Error bars represent standard deviation of triplicate microcosms.

phenomenon even in drinking water distribution systems (Xi et al., 2009), and has also recently been documented in a recycled water system (Ryu et al., 2005).

Several studies have documented levels of ARGs in WWTP effluents, providing a reference for comparison. Generally, ermF, sul1, sul2, tet $(\mathrm{A})$, and tet $(\mathrm{O})$ levels measured in the POE, POU, and WWTP effluent applied in the irrigation study were below or at the lower end of ranges reported by others in WWTP effluents (Kim et al., 2010; Czekalski et al., 2012; Negreanu et al., 2012). However, the irrigated soil in this study carried higher levels of sul1 (7.3 $\log _{10}$ copies/g) and sul2 (7.2 $\log _{10}$ copies/g) than reported by others in a field study of irrigation with recycled water (5.1-6.7 and 3.5-4.7 $\log _{10}$ copies/g, respectively; Negreanu et al., 2012).

The occurrence of $v a n \mathrm{~A}$ is of particular interest given that it confers resistance to vancomycin, a last-resort life-saving antibiotic. Vancomycin is commonly prescribed to treat methicillin-resistant Staphylococcus aureus (MRSA) infections, but has been losing effectiveness due to increased resistance among staphylococci (Stevens, 2006). vanA was detected in every sample in this study using primers targeting a 732-bp product. Interestingly, using vanA primers designed for longer target products
(1030 bp; Clark et al., 1993), vanA was detectable at several POU sites, but not in any POE samples (data not shown). Detection differences between the two PCR primer sets may indicate that vanA was partially damaged during disinfection, preventing amplification of longer PCR products. Long-amplicon PCR has recently been demonstrated to provide enhanced detection of DNA damage events (McKinney and Pruden, 2012). Few studies have reported detection of vanA in environmental samples, providing little reference for comparison. However, van A has been reported in drinking water biofilms and wastewater (Schwartz et al., 2003), but was below detection in wastewater reclaimed for groundwater recharge environments (Böckelmann et al., 2009). To the knowledge of the authors, this is the first report of the presence of vanA in distributed recycled water.

\section{MOLECULAR DETECTION OF WATERBORNE PATHOGENS AND INDICATORS}

Opportunistic pathogens residing in water systems, such as $L$. pneumophila and $P$. aeruginosa, are now the primary source of waterborne disease outbreak in developed countries (Brunkard et al., 2011). However, there is a need for epidemiological studies to better quantify the precise contributions of various water 
systems to human disease (Pruden et al., 2013). Of interest to the present study was whether such organisms may be present in recycled water, which could be of special concern for bacterial pathogens because they are capable of developing antibiotic resistance. $P$. aeruginosa is an example of an opportunistic pathogen that colonizes taps and is prone to multi-antibiotic resistant forms (Trautmann et al., 2005). E. coli was also of interest as a fecal indicator.

The mip gene, specific to L. pneumophila, was detectable at levels comparable to those recently observed in chloraminated drinking water distribution systems (Wang et al., 2012). Thus, there could be concern for aerosolization of L. pneumophila during spray irrigation. Future research is suggested to more closely examine this potential transmission pathway. gadAB, specific to E. coli, detected at POU in this study, was comparable to levels previously observed in manure runoff (4.6-4.9 $\log _{10}$ copies/mL, assuming one gene copy per cell) and higher than previously observed in WWTP effluent $\left(2.74 \log _{10}\right.$ copies/mL) (Grant et al., 2001). This combined with the observation of gadAB below detection at POE, but detectable at POU, is further evidence of bacterial re-growth within reclaimed water distribution systems.

\section{EFFECT OF DISINFECTION ON ARGS}

Chlorination is commonly applied to WWTP effluents during warm seasons, in which case the effluent must be dechlorinated prior to discharge. Chlorination had a significant impact on $16 \mathrm{~S}$ rRNA and sul2 gene copies, which is consistent with the expectation that chlorination would have a moderate reactivity with nucleic acids (Dodd, 2012). Although occasionally ARGs detected in dechlorinated effluent were not detected in chlorinated effluent, the levels of detected genes were not significantly different. The levels of ARGs in secondary, chlorinated, and dechlorinated WWTP effluent fractions were comparable to those detected at the POU in the field study (Figure 5).

\section{ARG FATE DURING WWTP EFFLUENT LAND APPLICATION}

In the lab study, periodic irrigation with secondary effluent increased the prevalence of sul1 and sul2 in historically manured soil compared to soil irrigated with chlorinated, dechlorinated, or DI water. This could be due to direct inputs of extracellular ARGs, intracellular ARGs, or horizontal gene transfer to native soil bacteria (Dodd, 2012). Interestingly, tet(O) or tet(W) levels in the soil slurry were not affected by irrigation. This highlights that different ARGs have different environmental fates, as has been observed recently with respect to sull and tet(W) in a watershed-scale study (Storteboom et al., 2010; Pruden et al., 2012). Differences in ARG fate likely relate to host properties and their overall propensity for horizontal gene transfer. Because $16 \mathrm{~S}$ rRNA gene copy levels were relatively consistent with time across the soil irrigation treatments (data not shown), changes in total bacterial population sizes were not likely a factor in the observed differences.

A recent field study carried out in Israel suggested that irrigation does not significantly affect the soil microbiome, and increases were not observed in sull, sul2, tet $(\mathrm{O})$, ermF, or ermB in soil subjected to long-term (6-12 years) irrigation with secondary effluent compared to freshwater irrigation (Negreanu et al., 2012). Given the difference in controls, irrigation frequency, soil type, climate, and wastewater chemistry, direct comparison between the studies is difficult. It is suspected that the difference in soil moisture and incubation time may likely be an important difference. Negreanu et al. (2012) irrigated with $4 \mathrm{~L}$ of water $/ \mathrm{m}^{2}$ soil/day which experienced a combination of infiltration, run off, and evaporation. In this study, soil-water slurries were used with irrigation waters that incubated with soil rather than infiltrating, allowing for greater contact time. Therefore, the microcosm results presented here may indicate that irrigating at high rates with secondary effluent may still result in amplified soil ARGs. The present study is consistent with the observation of increased ARG copies directly under irrigation drippers compared to soils $50 \mathrm{~m}$ from drippers (Negreanu et al., 2012). Further, soil type has been noted to be a critical factor in determining the level of impact of land application of biosolids containing ARGs (Munir and Xagoraraki, 2011), and may also affect the fate of ARGs applied by irrigation.

Understanding land use scenarios that affect soil ARGs is of utmost importance given that the resistome of multi-drug resistant soil bacteria was recently shown to match that from diverse human pathogens (Forsberg et al., 2012). Heavy irrigation with secondary effluent is shown here to be capable of increasing soil ARGs. In practice, given that ARG prevalence can increase between POE and POU within distribution systems, increased ARG levels in irrigation waters and therefore soils are expected. Given that spray irrigation of recreational fields with treated wastewater is common practice, there is considerable potential for human contact with aerosols and soil.

\section{CONCLUSION}

This study brings to light the occurrence of ARGs at the POU in recycled water irrigation systems, including vanA, which is of significant concern to human health. Differences between POE and POU ARG occurrences underscore the need to take into consideration re-growth that occurs in the distribution system when estimating overall exposure and risk. Based on the lab microcosm study, amplified levels of ARGs in soil irrigated with recycled water is possible. Molecular data in this study also indicates the potential presence of waterborne bacterial pathogens, such as $L$. pneumophila. As ARGs are emerging contaminants, risk assessment is in its infancy and no guidance yet exists on safe levels (Pruden, 2011). In addition to direct contact with water and aerosols during recreational activity, a greater concern may be overall contribution to the global pool of antibiotic resistance and ultimately reducing the effectiveness of available antibiotics for treating human disease.

\section{ACKNOWLEDGMENTS}

This work was funded by the Virginia Tech Institute for Critical Technology and Applied Science Award TSTS 11-26 and NSF Research Experience for Undergraduates site award \#1062860. Any opinions, findings, and conclusions or recommendations expressed in this paper are those of the author(s) and do not necessarily reflect the views of the sponsors. Gratitude is also extended to Chad McKinney and Mark Mazzochette for laboratory assistance and Andrew Hoegh for assistance with statistics. 


\section{REFERENCES}

Aminov, R., Garrigues-Jeanjean, N., and Mackie, R. (2001). Molecular ecology of tetracycline resistance: development and validation of primers for detection of tetracycline resistance genes encoding ribosomal protection proteins. Appl. Environ. Microbiol.67, 22-32.

Aminov, R. I., Chee-Sanford, J. C., Garrigues, N., Teferedegne, B., Krapac, I. J., White, B. A., et al. (2002). Development, validation, and application of PCR primers for detection of tetracycline efflux genes of Gram-negative bacteria. Appl. Environ. Microbiol. 68 1786-1793.

Anuj, S. N., Whiley, D. M., Kidd, T. J., Bell, S. C., Wainwright, C. E., Nissen, M. D., et al. (2009). Identification of Pseudomonas aeruginosa by a duplex real-time polymerase chain reaction assay targeting the ecf $X$ and the $g y r B$ genes. Diagn. Microbiol. Infect. Dis. 63, 127-131.

Auerbach, E. A., Seyfried, E. E., and McMahon, K. D. (2007). Tetracycline resistance genes in activated sludge wastewater treatment plants. Water Res. 41, 1143-1151.

Böckelmann, U., Dörries, H.-H., AyusoGabella, M. N., Salgot de Marçay, M., Tandoi, V., Levantesi, C., et al. (2009). Quantitative PCR monitoring of antibiotic resistance genes and bacterial pathogens in three European artificial groundwater recharge systems. Appl. Environ. Microbiol. 75, 154-163.

Brunkard, J. M., Ailes, E., Roberts, V. A., Hill, V., Hilborn, E. D., Craun, G. F., et al. (2011). Surveillance for waterborne disease outbreaks associated with drinking water - United States. MMWR Surveill. Summ. 60, 38-75.

Carlet, J., Jarlier, V., Harbarth, S., Voss, A., Goossens, H., and Pittet, D. (2012). Ready for a world without antibiotics? The pensières antibiotic resistance call to action. Antimicrob. Resist. Infect. Control 1, 11.

Chen, J., Yu, Z., Michel, F. C., Wittum, T., and Morrison, M. (2007). Development and application of real-time PCR assays for quantification of erm genes conferring resistance to macrolideslincosamides-streptogramin B in livestock manure and manure management systems. Appl. Environ. Microbiol. 73, 4407-4416.

Chen, Y.-C., Higgins, M. J., Maas, N. A., and Murthy, S. N. (2006). DNA extraction and Escherichia coli quantification of anaerobically digested biosolids using the competitive touchdown PCR method. Water Res. 40, 3037-3044.
Clark, N. C., Cooksey, R. C., Hill, B. C., Swenson, J. M., and Tenover, F. C. (1993). Characterization of glycopeptide-resistant enterococci from U.S. hospitals. Antimicrob. Agents Chemother. 37, 2311-2317.

Czekalski, N., Berthold, T., Caucci, S., Egli, A., and Buergmann, $\mathrm{H}$. (2012). Increased levels of multiresistant bacteria and resistance genes after wastewater treatment and their dissemination into Lake Geneva, Switzerland. Front. Microbiol. 3:106. doi: 10.3389/fmicb.2012. 00106

Dodd, M. C. (2012). Potential impacts of disinfection processes on elimination and deactivation of antibiotic resistance genes during water and wastewater treatment. J. Environ. Monit. 14, 1754-1771.

Dutka-Malen, S., Evers, S., and Courvalin, P. (1995). Detection of glycopeptide resistance genotypes and identification to the species level of clinically relevant enterococci by PCR. J. Clin. Microbiol. 33, 24-27.

Forsberg, K. J., Reyes, A., Wang, B., Selleck, E. M., Sommer, M. O. A., and Dantas, G. (2012). The shared antibiotic resistome of soil bacteria and human pathogens. Science 337, 1107-1111.

Grant, M. A., Weagant, S. D., and Feng, P. (2001). Glutamate decarboxylase genes as a prescreening marker for detection of pathogenic Escherichia coli groups. Appl. Environ. Microbiol. 67, 3110-3114

Grant, S. B., Saphores, J.-D., Feldman, D. L., Hamilton, A. J., Fletcher, T. D., Cook, P. L. M., et al. (2012). Taking the "waste" out of "wastewater" for human water security and ecosystem sustainability. Science 337 681-686.

Kim, S., Park, H., and Chandran, K. (2010). Propensity of activated sludge to amplify or attenuate tetracycline resistance genes and tetracycline resistant bacteria: a mathematical modeling approach. Chemosphere 78, 1071-1077.

LaPara, T. M., Burch, T. R., McNamara P. J., Tan, D. T., Yan, M., and Eichmiller, J. J. (2011). Tertiary-treated municipal wastewater is a significant point source of antibiotic resistance genes into Duluth-Superior harbor. Environ. Sci. Technol. 45, 9543-9549.

Ma, Y., Wilson, C. A., Novak, J. T., Riffat, R., Aynur, S., Murthy S., et al. (2011). Effect of various sludge digestion conditions on sulfonamide, macrolide, and tetracycline resistance genes and class I Integrons.
Environ. Sci. Technol. 45, 78557861.

McKinney, C. W., and Pruden, A. (2012). Ultraviolet disinfection of antibiotic resistant bacteria and their antibiotic resistance genes in water and wastewater. Environ. Sci. Technol. 46, 13393-13400.

McLain, J. T., and Williams, C. (2012). Assessing environmental impacts of treated wastewater through monitoring of fecal indicator bacteria and salinity in irrigated soils. Environ. Monit. Assess. 184, 1559-1572.

Munir, M., and Xagoraraki, I. (2011). Levels of antibiotic resistance genes in manure, biosolids, and fertilized soil. J. Environ. Qual. 40, 248-255.

Nazarian, E. J., Bopp, D. J., Saylors, A., Limberger, R. J., and Musser, K. A. (2008). Design and implementation of a protocol for the detection of Legionella in clinical and environmental samples. Diagn. Microbiol. Infect. Dis. 62, 125-132.

Negreanu, Y., Pasternak, Z., Jurkevitch, E., and Cytryn, E. (2012). Impact of treated wastewater irrigation on antibiotic resistance in agricultural soils. Environ. Sci. Technol. 46, 48004808.

Pruden, A. (2011). "Unique challenges in the health risk assessment of antibiotic resistance genes in the environment," in Society for Environmental Toxicology and Chemistry (SETAC) 32nd Annual Meeting, November 1316, Boston, MA.

Pruden, A., Arabi, M., and Storteboom, H. N. (2012). Correlation between upstream human activities and riverine antibiotic resistance genes. Environ. Sci. Technol. 46, 11541-11549.

Pruden, A., Edwards, M., and Falkinham, J. O. III. (2013). "State of the Science of opportunistic pathogens in premise plumbing: methodology, microbial ecology, and epidemiology," in Water Research Foundation Project 4379 Final Report. Denver, CO: Water Research Foundation.

Pruden, A., Pei, R., Storteboom, H., and Carlson, K. H. (2006). Antibiotic resistance genes as emerging contaminants: studies in Northern Colorado. Environ. Sci. Technol. 40, 7445-7450.

Rubiano, M.-E., Agulló-Barceló, M., Casas-Mangas, R., Jofre, J., and Lucena, F. (2012). Assessing the effects of tertiary treated wastewater reuse on a Mediterranean river (Llobregat, NE Spain), part III: pathogen and indicators. Environ. Sci. Pollut. Res. 19, 1026-1032.
Ryu, H., Alum, A., and Abbaszadegan, M. (2005). Microbial characterization and population changes in nonpotable reclaimed water distribution systems. Environ. Sci. Technol. 39, 8600-8605.

Schwartz, T., Kohnen, W., Jansen, B., and Obst, U. (2003). Detection of antibiotic-resistant bacteria and their resistance genes in wastewater, surface water, and drinking water biofilms. FEMS Microbiol. Ecol. 43, 325-335.

Stevens, D. L. (2006). The role of vancomycin in the treatment paradigm. Clin. Infect. Dis. 42, S51-S57.

Storteboom, H., Arabi, M., Davis, J. G., Crimi, B., and Pruden, A. (2010). Tracking antibiotic resistance genes in the South Platte River basin using molecular signatures of urban, agricultural, and pristine sources. Environ. Sci. Technol. 44, 7397-7404.

Suzuki, M. T., Taylor, L. T., and DeLong, E. F. (2000). Quantitative analysis of small-subunit rRNA genes in mixed microbial populations via $5^{\prime}$-nuclease assays. Appl. Environ. Microbiol. 66, 4605-4614.

Trautmann, M., Lepper, P. M., and Haller, M. (2005). Ecology of Pseudomonas aeruginosa in the intensive care unit and the evolving role of water outlets as a reservoir of the organism. Am. J. Infect. Control 33, S41-S49.

US Environmental Protection Agency (USEPA). (2012). Guidelines for Water Reuse. Washington, DC: USEPA.

Wang, H., Edwards, M., Falkinham, J. O., and Pruden, A. (2012). Molecular survey of the occurrence of Legionella spp., Mycobacterium spp., Pseudomonas aeruginosa, and Amoeba hosts in two chloraminated drinking water distribution systems. Appl. Environ. Microbiol. 78, 62856294.

Webber, M. A., and Piddock, L. J. V. (2003). The importance of efflux pumps in bacterial antibiotic resistance. J. Antimicrob. Chemother. 51, 9-11.

Xi, C., Zhang, Y., Marrs, C. F., Ye, W., Simon, C., Foxman, B., et al. (2009). Prevalence of antibiotic resistance in drinking water treatment and distribution systems. Appl. Environ. Microbiol. 75, 5714-5718.

Conflict of Interest Statement: The authors declare that the research was conducted in the absence of any commercial or financial relationships that could be construed as a potential conflict of interest. 
Received: 01 March 2013; accepted: 06 May 2013; published online: 28 May 2013.

Citation: Fahrenfeld N, Ma Y, O'Brien $M$ and Pruden A (2013) Reclaimed water as a reservoir of antibiotic resistance genes: distribution system and irrigation implications. Front. Microbiol. 4:130. doi: 10.3389/fmicb. 2013.00130

This article was submitted to Frontiers in Antimicrobials, Resistance and
Chemotherapy, a specialty of Frontiers in Microbiology.

Copyright (c) 2013 Fahrenfeld, Ma, O'Brien and Pruden. This is an openaccess article distributed under the terms of the Creative Commons Attribution
License, which permits use, distribution and reproduction in other forums, provided the original authors and source are credited and subject to any copyright notices concerning any third-party graphics etc. 